PS3-D-paper4

\title{
A longitudinal study of physics students' conceptions of force in pre-service training for high school teachers
}

\author{
Ricardo Trumper, Oranim \\ University Division, Haifa University, Israel
}

\begin{abstract}
.
Do Physics students in pre-service training to be high-school teachers hold the accepted scientific views which will eventually allow them to plan and implement instructional strategies which, in turn, will lead their future students to achieve a scientific concept of force? The results of a longitudinal study dealing with this issue will be discussed. The most important findings of this study can be summarized as follows. Physics students in pre-service training for high school teachers:
\end{abstract}

1. Mostly do not succeed to abandon their Aristotelian 'impetus' misconception.

2. Have difficulties in recognizing the reaction as a force.

3. Are rather ambivalent when referring to the necessity of the forces to be balanced in static situations.

4. Hold the concept that an initial force exerted on an object, keeps it going and gradually lessens - the "fading-away" concept.

5. Hold the concept that a force (inertia) acts on moving objects resisting a push.

6. Tend to return in 4th year to intuitive views of force, rather than holding the accepted scientific concept.

\section{Introduction.}

Knowing more about teachers' preconceptions in science has become increasingly recognized as essential and some important research has been carried out in this field (Weinstein, 1989). According to the constructivist perspective, humans are seen as subjects who actively construct understanding from experiences using their already existing conceptual frameworks (Wubbels, 1992). A constructivist way of teaching assumes the existence of learners' conceptual schemata and the active application of these when responding to and making sense of new situations. Applied to science education, this constructivist view supports teachers who are concerned with the investigation of students' ideas and who develop ways which incorporate these viewpoints into a learning-teaching dialogue. Do teachers, however, hold the accepted scientific view of the force concept themselves and are they, in fact, aware of their students' alternative conceptual frameworks?

Berg and Brouwer (1991) carried out a study on Canadian high school physics teachers awareness of students alternate conceptions about rotational motion and gravity. They found that the teachers were mainly unaware of students' alternate conceptions about gravity. They also saw that over one third of the teachers held one or more alternate conceptions themselves. They claimed that "It is likely that some of those alternate conceptions have been passed on to students, as they were related to phenomena commonly discussed during a high school physics course.

Kruger, Palacio and Summers (1992) conducted a comprehensive research into British elementary teachers' conceptions of force. They found that many of the 
respondents were uncertain about what counts as a force in static situations. Three forces in particular caused problems:

1. reaction - many teachers did not recognize that a table or the ground is considered by scientists to exert an upward force on objects;

2. friction - many teachers were uncertain about the status of friction as a force;

3. weight - a substantial number of teachers were unsure of the status of weight as a force or denied that it was a force, while well over half the sample did not identify weight with gravity.

They found also that the idea of adding forces to produce a resultant force was new to many of the teachers. Moreover, responses to dynamic situations revealed that:

1. virtually none of the primary school teachers had a correct (in the Newtonian sense) view of the instances involving forces and motion with which they were presented;

2. a large number of primary school teachers agreed with statements which implied a belief in a naive impetus theory.;

3. many of the teachers did not differentiate between concepts that are distinct according to the generally accepted scientific viewpoint, e.g., force, momentum and movement.

In a recently published cross-college age study, Trumper and Gorsky (1996) found that physics students: (a) hold the Aristotelian 'impetus' misconception to a great extent, (b) think to a great extent that a force (inertia) acts on moving objects resisting a push, (c) have difficulties in knowing the direction of weight and are inconsistent in identifying the concepts of gravity and weight, and (d) believe to a great extent that the initial force keeping an object going gradually lessens.

How Physics student teachers' understanding of force develops during their preservice high-school teacher programs? Do they finally hold the accepted scientific views which will eventually allow them to plan and implement instructional strategies which, in turn, will lead their future students to achieve a correct scientific concept of force? The results of a longitudinal study dealing with this issue will be discussed in the following sections.

\section{A longitudinal study.}

Participants in the present study were drawn from the largest college in Israel which conducts a 4-year pre-service training program for future high-school teachers. The study was held during four consecutive years, comprising 25 students. This population included more than $90 \%$ of the students who learned in the four last years in an Israeli university program which was intended to lead them to a B. Sc. degree in Physics and a high-school teaching certificate.

The force conceptions held by the Physics students were analyzed by means of a two-part written questionnaire which was presented during the first day of class. The first part of the questionnaire included seven questions in which students were presented with different pictures and were asked to draw arrows showing each of the forces acting on the objects in question and to name each force.

The second part of the questionnaire comprised 44 statements together with drawings of different situations. Participants were asked to respond to each 
statement with one of the following responses: true, false, don't understand or not sure. This part of the questionnaire was intended to identify students' views in terms of those currently accepted by scientists and to reach a broader understanding of students' intuitive views of force.

\section{Findings.}

The Chi-square coefficient was calculated in order to compare correct and incorrect answers of students through the years, and in most cases, statistically significant differences were found among the years. The main findings of this study can be summarized as follows. Physics students in pre-service training for high school teachers:

1. Mostly do not succeed to abandon their Aristotelian 'impetus' misconception. This may be the reason why they fail considerably to affirm that the forces acting on an object are balanced during uniform motion. Moreover, they have great difficulties when referring that motion and force need not be in the same direction.

2. Have difficulties in recognizing the reaction as a force, mainly while referring to moving objects on solid surfaces (like, 'a book moving on a table').

3. Are rather ambivalent when referring to the necessity of the forces to be balanced in static situations.

4. Hold, to a great extent, the concept that an initial force exerted on an object, keeps it going and gradually lessens - the "fading-away" concept (diSessa, 1983).

5. Hold, to a great extent, the concept that a force (inertia) acts on moving objects resisting a push.

6. Tend to return in 4 th year to intuitive views of force, rather than holding the accepted scientific concept.

There is clearly a need for student teachers' ideas about force to be moved from these perspectives toward the scientific view if they are to lead children toward a coherent perception of the force concept and assess their level of understanding.

\section{References.}

Berg, T. and Brouwer, W. (1991). Teacher awareness of student alternate conceptions about rotational motion and gravity. Journal of Research in Science Teaching, 28, 3-18.

diSessa, A. (1983). Phenomenology and the evolution of intuition. In D. Gentner \& A. Stevens (Eds.), Mental Models. (Erlbaum, Hillsdale, New Jersey).

Kruger, C., Palacio, D. and Summers, M. (1992). Survey of English primary teachers' conceptions of force, energy and materials. Science Education, 76, 339-351.

Trumper, R. and Gorsky, P. (1996). A cross-college age study about physics students' conceptions of force in pre-service training for high school teachers. Physics Education, 31, 227-36.

Weinstein, C. (1989). Teacher education students' preconceptions of teaching Journal of Teacher Education, 39, 53-60.

Wubbels, T. (1992). Taking account of student teachers' preconceptions. Teaching and Teacher Education, 8, 137-49. 